DOSSIÊ TEMÁTICO: Perspectivas para pensar as cidades: infâncias, educação, democracia e justiça

d०1 https://doi.org/10.22481/praxisedu.v16i40.6897

\title{
O DIREITO DE BRINCAR: UMA NECESSIDADE PARA AS CRIANÇAS, UMA POTENCIALIDADE PARA A ESCOLA E A CIDADE ${ }^{1}$
}

\author{
THE RIGHT TO PLAY: A NECESSITY FOR CHILDREN, A POTENTIAL FOR SCHOOL \\ AND THE CITY
}

\author{
EL DERECHO AL JUEGO: UNA NECESIDAD PARA LOS NIÑOS, UN POTENCIAL \\ PARA LA ESCUELA Y LA CIUDAD
}

\section{IL DIRITTO DI GIOCARE: UNA NECESSITÀ PER I BAMBINI, UN POTENZIALE PER SCUOLA E LA CITTÀ}

Francesco Tonucci Instituto de Ciências e Tecnologias da Cognição - Itália Conselho Nacional de Pesquisa - Itália

\begin{abstract}
Resumo: A principal questão abordada neste artigo é: por que e como a brincadeira infantil deve ser considerada um critério importante nas políticas urbanas? Uma possível resposta para este problema é encontrada ao longo do texto. Gostaria de começar esboçando a evolução mais recente (ou melhor, involução) da estrutura e organização urbana, enfatizando como ela define um ambiente que é proibido e hostil às crianças, a menos que sejam acompanhados por adultos; vou resumir o impacto desse ambiente no jogo e, portanto, no desenvolvimento das crianças, acentuando as diferentes características da mobilidade espacial em crianças e adultos, e o extremo perigo de isolar as crianças da experiência do perigo. Proporei uma alternativa radical à política urbana na qual as crianças e seu jogo são o foco principal, em vez de um problema marginal e não conhecido para ser considerado apenas como uma reflexão posterior, e apresentarei alguns casos concretos naqueles em que tal alternativa foi colocada em prática por crianças e políticos juntos, e seus efeitos foram testados e avaliados. Em conclusão, experiências semelhantes parecem justificar uma quantidade moderada de esperança para o futuro de nossas cidades, apesar de suas preocupantes condições atuais.
\end{abstract}

Palavras chave: Crianças; Direito de brincar; Escola; Cidade.

\begin{abstract}
The main question addressed in this article is: why and how should child play be considered an important parameter in urban policies? A possible answer to this problem is found throughout the text. I would like to begin by drawing the most recent evolution (or rather involution) of urban structure

\footnotetext{
${ }^{1}$ Tradução livre do original em italiano por Marcia Aparecida Gobbi e revisão técnica de Cleriston Izidro dos Anjos. Fazemos, aqui, um especial agradecimento à Professora Doutora Daniela Finco (UNIFESP) que, muito generosamente, colaborou com o processo de tradução deste artigo.
} 
and organization, emphasizing how it defines an environment that is forbidden and hostile to children, unless they are accompanied by adults; I will summarize the impact of this environment on the game and therefore on the development of children, accentuating the different characteristics of spatial mobility in children and adults, and the extreme danger of isolating children from the experience of danger. I will propose a radical alternative to urban policy in which children and their play are the main focus, rather than a marginal problem and not known to be considered only as a later reflection, and I will present some concrete cases in those where such an alternative was put into practice by children and politicians together, and its effects were tested and evaluated. In conclusion, similar experiences seem to justify a moderate amount of hope for the future of our cities, despite their worrying current conditions.

Keywords: Childreen, City, School, right to play

Resumen: La pregunta principal que se aborda en este artículo es: ¿por qué y cómo se debe considerar el juego infantil un parámetro importante en las políticas urbanas? Una posible respuesta a este problema se encuentra en todo el texto. Me gustaría comenzar dibujando la evolución más reciente (o más bien involucionada) de la estructura y organización urbana, haciendo hincapié en cómo define un entorno que está prohibido y hostil a los niños, a menos que vayan acompañados de adultos; Resumiré el impacto de este entorno en el juego y, por lo tanto, en el desarrollo de los niños, acentuando las diferentes características de la movilidad espacial en niños y adultos, y el peligro extremo de aislar a los niños de la experiencia del peligro. Propondré una alternativa radical a la política urbana en la que los niños y su juego sean el foco principal, más que un problema marginal y no se sepa que sólo se considere como una reflexión posterior, y presentaré algunos casos concretos en aquellos en los que los niños y los políticos pusieron en práctica una alternativa de este tipo, y sus efectos fueron probados y evaluados. En conclusión, experiencias similares parecen justificar una cantidad moderada de esperanza para el futuro de nuestras ciudades, a pesar de sus preocupantes condiciones actuales.

Palabras clave: ciudad, derecho al juego, escuela, niños

Riepilogo: Il principale interrogativo affrontato nell'articolo: perché e come il gioco dei bambini dovrebbe essere considerato un importante parametro nelle politiche urbane? Una possibile risposta a questo problema si trova in tutto il testo. Voglio iniziare tratteggiando la più recente evoluzione (o piuttosto involuzione) della struttura e della organizzazione urbana enfatizzando come questa definisce un ambiente che è proibito ed ostile per i bambini a meno che siano accompagnati dagli adulti; riassumerò l'impatto di un simile ambiente sul gioco e quindi sullo sviluppo dei bambini, accentuando le diverse caratteristiche della mobilità spaziale nei bambini e negli adulti, e l'estremo pericolo di isolare i bambini dall'esperienza del pericolo che costituisce una caratteristica paradossale della educazione di oggi. Proporrò un'alternativa radicale alla corrente politica urbana in cui i bambini e il loro gioco sono il principale focus, piuttosto che un marginale e non conosciuto problema da essere considerato solo come un ripensamento, e presenterò alcuni casi concreti nei quelli una simile alternativa è stata messa in pratica da bambini e politici insieme, e i suoi effetti sono stati testati e valutati. In conclusione esperienze simili sembrano giustificare una moderata quantità di speranza per il futuro delle nostre città, nonostante le loro preoccupanti condizioni attuali.

Parole chiave: bambini, scuola, diritto a giocare, cità.

Aqueles que governam uma cidade tomam decisões que aparentemente dizem respeito a aspectos concretos e cotidianos da vida das pessoas, como transporte, moradia, serviços. De fato, essas escolhas incidem em um problema fundamental que diz respeito à felicidade dos 
cidadãos. A cidade pode enfrentar problemas como o trânsito, a velocidade das viagens e a defesa dos espaços públicos como prioridades e, com isso, abandonar as necessidades de comunicação, intercâmbio e serenidade, especialmente para os cidadãos mais vulneráveis. É possível também considerar prioritário garantir o direito de brincar e de mobilidade às crianças e idosos, buscar segurança na solidariedade e participação, defender a estética urbana como um bem indispensável. O prefeito de Curitiba, no Brasil, por exemplo, disse que conseguiu equipar todos os distritos da cidade com bibliotecas públicas e fornecer-lhes uma boa quantidade de livros, renunciando à construção de um quilômetro de rodovia. Como prova de que os gastos com crianças não são um custo real, mas um investimento produtivo também do ponto de vista econômico, Kofi Annan, presidente das Nações Unidas, em 8 de maio de 2002, em Nova York, abrindo a Sessão Especial da ONU para Crianças, encerrou seu discurso dizendo: "Como podemos falhar, especialmente agora que sabemos que cada dólar investido na melhoria das condições das crianças tem um retorno de até 7 dólares para toda a sociedade?" São escolhas da filosofia de governo da cidade.

O objetivo principal deste artigo consiste na defesa de que as crianças brinquem de acordo com suas necessidades (e não conforme permitido por uma cidade adaptada apenas às necessidades do adulto) e que isto garante cidadãos adultos mais saudáveis, mais serenos e mais produtivos. Em outras palavras, brincar, é, sem dúvida, um aspecto fundamental das políticas urbanas. Mas, por quê?

Esta é a principal questão abordada no artigo: por que e como a brincadeira infantil deve ser considerada um critério importante nas políticas urbanas? Uma possível resposta para este problema é apresentada do seguinte modo: começo por esboçar a evolução mais recente (ou melhor, involução) da estrutura e organização urbana (cf.1), enfatizando o que define um ambiente proibido e hostil para as crianças, caso não estejam acompanhadas de adultos (cf. 2); comentarei sobre o impacto desse ambiente no brincar e, portanto, no desenvolvimento das crianças (cf. 3), acentuando as diferentes características da mobilidade espacial em crianças e adultos (cf. 4), e o perigo extremo de isolar as crianças da experiência de risco que é uma característica paradoxal da educação atual (cf. 5). Proporei uma alternativa radical à política urbana na qual as crianças e o brincar são o foco principal, em vez de um problema marginal e desconhecido (cf. 6), e apresentarei alguns casos concretos e alternativas colocadas em prática por crianças e políticos em conjunto, cujos efeitos foram testados e avaliados (cf. 7). Em conclusão, experiências semelhantes parecem justificar uma moderada quantidade de esperança para o futuro de nossas cidades, apesar de suas preocupantes condições atuais (cf. 8). 


\section{O desenvolvimento das cidades: uma breve análise}

A cidade moderna nasceu quebrando o padrão medieval que separava o castelo da vila e criou uma relação hierárquica entre eles. Nasceu em torno de uma praça, em um espaço compartilhado, apesar da diversidade de classes e condições. O prédio do governo, a catedral, o quartel da guarnição têm vista para a praça e é nela onde o comércio acontece. A cidade é o local de encontro e troca. $\mathrm{O}$ espaço urbano é compartilhado, não existem bairros diferentes para diferentes níveis sociais: nas ruas da cidade, o palácio dos nobres, frequentemente obra de grandes arquitetos, fica ao lado das casas dos humildes artesãos. Essa alternância constrói um ritmo urbano que conferem beleza a muitas cidades europeias.

Nas últimas dezenas de anos, após a Segunda Guerra Mundial, parece que a cidade voltou ao modelo medieval: a rica cidade velha se esvazia, torna-se espaço de atividades comerciais e terciárias, e é cercada por uma nova vila, mais esquálida e dura do que a antiga, os subúrbios pobres e às vezes miseráveis com casas anônimas ou barracos, que dependem da cidade rica para sua sobrevivência. O centro rico é defendido pela polícia com câmeras fixas e inúmeras empresas de segurança privada.

A cidade renunciou a ser um local de encontro e relações e escolheu a separação e $a$ especialização como novos critérios de desenvolvimento. Da especialização de espaços e habilidades resultaram lugares diferentes para diferentes pessoas e para diversas funções. A cidade velha para bancos, lojas de luxo, diversão; a periferia para dormir. Há os lugares das crianças, o berçário, o playground, a brinquedoteca; os lugares para o antigo, o hospício, o centro dos idosos; locais de conhecimento, do jardim de infância à universidade; lugares especializados para compras, o supermercado, o shopping, os hospitais e os locais da doença ${ }^{2}$ (BOZZO, 1995).

\section{Uma cidade sem crianças}

Tempos atrás não se via a hora de sair de casa, porque tudo o que mais importava estava fora dela. A casa era o lugar fundamental de segurança, das necessidades básicas, de cumprir tarefas de casa. Mas necessitava-se sair para encontrar amigos, para brincar, para ir ao bar, ao cinema, à biblioteca. E se havia perigos, como havia, tinha-se que ter cuidado, assim disseram nossos pais.

${ }^{2}$ Mumford chama os hospitais de “ Os depósitos de doenças” (MUMFORD, 1945). 
Hoje estamos ansiosos para voltar para casa, pois a casa é o lugar do descanso, da cultura, do afeto, da comunicação. Em casa temos alimentos congelados, temos a biblioteca, a coleção de CDs, filmes favoritos, a capacidade de falar por telefone ou trocar mensagens e fotos para a internet ou celular. A casa é parte insuficiente da realidade mais ampla da cidade, mas resume a própria cidade. Já não faz parte de um ecossistema complexo, mas tende a autossuficiência, outra característica importante e perturbadora da cidade moderna. As várias partes da cidade tendem à autossuficiência, da casa ao shopping.

Antes, comprar significava pegar um caminho, entrar em lugares diferentes, encontrar várias pessoas para que pudéssemos adquirir confiança, uns nos outros, ou trocar as últimas notícias. Atualmente para comprar se faz uma transferência de dinheiro ou produtos para outra área da cidade, ou melhor, para outra cidade pequena e eficiente, onde se pode comprar tudo: o Centro comercial. Uma cidade com estacionamento garantido e, portanto, sem carros circulando, com ruas e praças pequenas seguras para as crianças. Muitas vezes, nestas cidades são pensados espaços com assistência e dedicados às pessoas; onde seja possível comer, ir a bancos, ao cabeleireiro e, claro, comprar. Muitas famílias consideram estes espaços um bom lugar para passar o fim de semana juntos. A degradação torna a cidade inabitável, e nos defendemos construindo locais seguros e protegidos, onde podemos passar nosso tempo livre com tranquilidade. Essa é uma tendência constante na cidade atual, coerente com a lógica de separação e especialização: criação de serviços, estruturas cada vez mais independentes e autossuficientes. É o caso do hospital, do estádio, dos principais museus, do campus universitário (GERMANOS, 1995; TAYLOR ET AL., 1998; BAUMANN, 2000).

Além disso, nas últimas décadas, a cidade se tornou um espaço reservado de fato para carros. Estes invadiram os espaços públicos, privatizando-os, afastando-os do possível uso daqueles que se deslocam a pé ou de bicicleta. As ruas e praças são locais de trânsito e estacionamento para veículos particulares, já não são mais espaços públicos que fazem de um grupo de casas particulares uma cidade. Os carros sempre têm direito, são os pedestres que, para atravessar a rua, devem descer a calçada, descer as passagens subterrâneas ou subir nas passagens superiores exclusivas às pessoas. Os pedestres, que também podem ser pequenos, idosos, deficientes, carregados de sacolas de compras, com uma criança nos braços ou no carrinho, têm a rota mais longa e extenuante.

Os carros vão sempre na rua plana, no nível zero. Os carros impõem sua lógica, sua estética, sua "música" nas cidades. Além dos carros, nossas principais cidades devem abrigar sinais de trânsito, placas e faixas verticais em calçadas antigas que poluem visualmente os monumentos e centros históricos (GARLING; VALSINER; 1985). 
Todas essas coisas aconteceram em muito pouco tempo. A cidade e seus administradores escolheram como cidadão protótipo, um cidadão do sexo masculino, adulto, trabalhador e motorista. Adaptaram a cidade às suas necessidades, tentou corresponder às suas demandas, garantindo assim o consentimento eleitoral do cidadão forte. Traiu, assim, as necessidades e os direitos daqueles que não são homens, não são adultos, não são trabalhadores, não são motoristas. Como resultado, essas cidades são cidades sem crianças. Nesta cidade a criança não pode viver algumas experiências fundamentais para seu desenvolvimento como aventura, pesquisa, descoberta, risco, superação do obstáculo e, portanto, satisfação, emoção $(\mathrm{LYNCH}, 1979)^{3}$. Ela não pode brincar. Essas experiências precisam de duas condições fundamentais que desapareceram: o lazer e um espaço público compartilhado. É difícil para a criança sair de casa sozinha, procurar companheiros e ir para um lugar adequado para brincar com eles. As dificuldades ambientais, verdadeiras ou presumidas, convenceram os pais de que esta cidade não permite que uma criança de seis e dez anos saia sozinha e, portanto, seu tempo livre foi transformado em tempo organizado e dedicado a diferentes atividades, em casa ou fora dela, rigorosamente agendadas e geralmente pagas. De um lado, portanto, televisão, play station, internet, de outro os diversos cursos vespertinos em esportes, arte e línguas estrangeiras (MARILLAUD, 1991).

E brincar? Para brincar os pais acompanham a criança até o jardim equipado perto da casa ou a acompanham até a casa de amigos ou convidam seus amigos para casa. Eles as esperam e as vigiam.

\section{No início vem o jogo}

Vendo nossos filhos tão bem vestidos, bem alimentados e capazes de manipular dispositivos tão complexos, falando línguas estrangeiras tão cedo, praticando esportes, respeitando as regras e conhecendo sua astúcia desde os primeiros anos, nós, adultos, muitas vezes pensamos que eles são apenas sortudos, pois podem fazer um monte de coisas que não nos permitiram, seja porque não estávamos lá, seja porque não havia dinheiro, ou ainda, porque nossos pais não entendiam essas coisas. Mas, atualmente, nossos filhos não podem correr, se soltar, se sujar, fazer coisas estranhas e às vezes proibidas, como fizemos na idade deles.

\footnotetext{
${ }^{3}$ Nesta análise crítica, nunca devemos esquecer quais melhorias significativas nas condições de vida (dos cidadãos em geral e das crianças em particular) caracterizam as sociedades contemporâneas, em comparação com os sistemas sociais e econômicos anteriores. No entanto, é precisamente à luz de tal progresso que não podemos aceitar passivamente a violação dos direitos primários descritos neste ensaio, que está principalmente subordinado a interesses egoístas e econômicos.
} 
Adultos pensam que atualmente seus filhos sabem muito mais coisas, que eles são mais inteligentes por acessarem essas atividades.

Uma menina de 10 anos do Conselho da Criança de Roma, discutindo o peso diferente que o direito de brincar e o direito à educação têm na vida das crianças, resume bem esse pensamento adulto quando diz: "Para os professores o estudo é importante porque nos prepara para o futuro, ao contrário, brinca-se somente quando se é criança e por isso não vale nada". Contra essa atitude desatenta dos adultos, que esqueceram o valor de suas experiências de infância, o jogo assume uma importância fundamental tanto na história dos homens quanto na história pessoal de cada mulher e de cada homem.

Huizinga, no final da década de 1930, analisou a atividade lúdica como antecipação e fundante da cultura e das culturas humanas: "O jogo é mais antigo que a cultura, porque o conceito de cultura, embora possa ser definido como insuficiente, pressupõe em todos os sentidos a convivência humana, e os animais não esperaram que os homens os ensinassem a brincar" (Huizinga 1939, p. 3). E Callari Galli, como se resumisse o longo debate, escreveu:

A atividade lúdica está presente em todos os grupos humanos, mesmo que o alcance de suas variações seja muito amplo; está mais presente em algumas idades, mesmo que geralmente acompanhe toda a vida de um indivíduo e difere de acordo com gênero, emprego, riqueza; segue as mudanças na sociedade, no entanto, apresentando permanências surpreendentes e grande continuidade temporal. Em alguns aspectos e em certas circunstâncias é uma atividade que parece estar desvinculada dos interesses materiais e contingentes, tendo um propósito em si, delimitado em termos de tempo e espaço, de acordo com regras livremente aceitas e absolutamente vinculantes. E todos os jogos parecem exigir a compreensão dos participantes de que o que você faz não é o que parece ${ }^{4}$ (CALLARI GALLI, 2002, p. 14)

Assim como se supõe que o jogo precede e funda a cultura humana, com certeza podese dizer que o jogo sustenta o desenvolvimento individual de cada mulher e de cada homem. Nas pesquisas científicas sobre o desenvolvimento humano entende-se que nos primeiros dias, meses e anos de vida que há um desenvolvimento mais rápido. É desde o nascimento que há uma explosão de experiências, não aos seis anos com o início do que se considera a idade da razão, como parece crer parte dos adultos, pais e professores. Antes de entrarem numa sala de aula pela primeira vez, as coisas importantes já aconteceram às crianças: aprendizados fundamentais a partir dos quais todo o conhecimento subsequente terá que ser construído.

Mas como pode ser explicado um fenômeno tão desconcertante? Nos primeiros anos de vida não há professores, não são utilizados materiais ou programas didáticos, então a que

${ }^{4}$ Introdução a Sutton-Smith (2002, p. 14). 
podemos atribuir o mérito de um crescimento tão importante? Parece-me que não podemos deixar de reconhecer neste (também) o papel da atividade mais significativa desses primeiros anos: o jogo. Por que essa atividade infantil tem um poder tão grande?

A criança vive na brincadeira experiências raras na vida do homem, como a de confrontar-se com a complexidade do mundo. Ela, vive com toda sua curiosidade, com tudo o que sabe e pode fazer, e com tudo o que não sabe e quer saber, na frente do mundo com todos os seus estímulos, suas novidades, seu charme. E brincar significa esculpir um pedaço deste mundo o tempo todo: uma peça que incluirá um amigo, objetos, regras, um espaço para ocupar, um tempo a ser administrado, riscos a tomar e com total liberdade, porque o que você não pode fazer, você pode inventar. Com uma liberdade substancial em relação às restrições e limitações da realidade: o que não existe pode ser imaginado, o que não é possível pode ser inventado. "Eu era um príncipe medieval" pode afirmar uma criança e a partir desse momento, se outros aceitarem a ficção, você se muda para outra era e respeita suas ${ }^{5}$ regras, suas condições. A vassoura será para todos um cavalo, o governante uma adaga, a cabana ou a árvore ou as escadas de um castelo. Realiza-se assim o significado de autonomia, qual seja, a capacidade de governar sobre as próprias leis, a capacidade de se entregar, de inventar novas regras.

É graças a essa complexidade que, nos primeiros anos, os aprendizados mais importantes de toda a vida do homem são realizados. E nenhum adulto será capaz de prever ou medir a quantidade de aprendizado de uma criança brincando e isso sempre será diferente e provavelmente maior do que podemos imaginar. Ninguém será capaz de planejar ou acelerar esse processo, impedi-lo ou empobrecê-lo. Talvez fosse mais útil para as crianças que esse conhecimento permanecesse oculto porque, conhecendo-o, poderia vir à mente dos adultos o desejo de ajudá-los, apoiá-los com ensinamentos e materiais didáticos adequados, como já começou a ser feito com os chamados "brinquedos inteligentes". Faltaria assim, a condição principal desta relação, isto é, que os adultos “deixem as crianças criarem”, "deixem brincar". A brincadeira da criança, antes e fora da escola é compreendida por muitos como "perder tempo", mas, pode ser entendida como perder-se no tempo, é encontrar com o mundo em uma relação emocionante, cheia de mistério, risco, aventura. $\mathrm{O}$ prazer é o motor disto, o mais potente já conhecido pelo homem. É por isso que uma criança quando brinca esquece de comer. O jogo livre e espontâneo da criança se assemelha às experiências mais elevadas e extraordinárias do adulto como as da pesquisa científica, exploração, arte, misticismo; as experiências de quando

\footnotetext{
5 "É essa atitude não literal que permite que o jogo seja desvinculado de suas consequências: na verdade, permite
} que o jogo seja um jogo." (GARVEY, 1977, p. 15). 
o homem se depara com a complexidade, quando ele encontra novamente a possibilidade de se deixar levar pelo grande motor do prazer (BATESON, 1956; BENCIVENGA, 1995; BRUNER, 1976).

Propostas educativas, também necessárias, se movem, ao contrário, a um nível mais baixo, menos estimulante e, portanto, menos produtivo. Na proposta educacional, o aluno é privado da emoção de encontrar a complexidade e a emoção de esculpir, ele mesmo, uma parte dela. É o adulto quem propõe ao aluno uma parte desse mundo complexo, de tal forma que a atividade solicitada produz com confiança e no prazo as aprovações desejadas. Esse pedaço do mundo perde todo o charme e mistério, torna-se incompreensível, tão desapegado de tudo o resto, e serve apenas para aprender. Para ter mais certeza do resultado, educadores adultos muitas vezes substituem a complexidade do mundo real pela complexidade mais controlável do ensino, do exercício, do livro didático. O controle é absoluto e geralmente o resultado é ruim, quase sempre menor do que o esperado e contraditório: ao aprender o aluno rejeita o que lhe ensinam, não o torna seu, não muda graças a isso. Nasce um bom aprendizado, que serve apenas na escola, até o último tema em sala de aula, até o último concurso e basta. A escola, com essa simplificação, com a segurança de sua programação, perdeu completamente sua relação com o prazer e deve recorrer a um motivador muito menos potente e eficaz, o do dever.

Estudo e trabalho veem primeiro. Eles são creditados como comportamentos "éticos" enquanto o jogo e o brincar, que estão profundamente ligados ao prazer, são banalizados como infantis, improdutivos, opcionais. Talvez, seja por isso que o jogo infantil esteve no presente recente elevado à "dignidade" do consumo e, portanto, de alguma forma libertado de suas características peculiares de futilidade e gratuidade. Talvez, seja por isso que a brincadeira infantil goza e sofre de modo similar às marginalizações sofridas por filósofos, artistas, pesquisadores, cientistas. Essa sociedade não tolera que sua atividade seja livre, inútil e ligada ao princípio do prazer.

\section{Eu iria devagar em direção a uma fonte}

Vamos tentar seguir dois caminhos: o de uma criança em movimento segurada pela mão de um adulto e a de uma criança se movendo sozinha. No primeiro caso a criança não toma nenhuma decisão, ou melhor, não pode tomar qualquer decisão. Se ela tentar parar, pegar alguma coisa, mudar a rota, ela geralmente é chamada de volta com as exortações habituais: "Não pare o tempo todo!", "Vamos, estamos atrasados!", "Não toque que você se suja!" Para o adulto, movê-lo é uma transferência de um ponto de partida para um ponto final, no menor 
tempo possível, sem incidentes ou imprevistos. Não é por acaso que os sistemas considerados mais eficientes para viagens são o metrô, a rodovia e a aeronave. Sistemas que com o menor número de "distrações" possíveis fazem chegar ao destino no menor tempo possível. Este é o objetivo da viagem, o principal interesse do adulto. O trajeto, em si, é uma perda de tempo, deve ser comprimido cada vez mais. As pessoas estão dispostas a gastar quantias incríveis para reduzir a viagem de trem de quatro horas entre Roma e Milão em trinta minutos!

No segundo caso a criança está sozinha, ela pode decidir, de fato, caso contrário ela deve voltar para casa imediatamente. A cada passo ela tem que tomar decisões diferentes: se deve continuar, se deve mudar de direção, parar para observar algo, se deve coletar algum objeto que lhe interesse. E cada decisão que ela toma tem consequências: se ela parar terá que levar em conta o tempo, caso contrário ela vai se atrasar, se ela pegar algo vai ter que escondê-lo porque a mãe pode não querer, se mudar de direção terá que tomar cuidado para tomar nota de alguns indicadores que podem ajudá-lo em seu caminho de volta. Note-se que os indicadores úteis para o retorno devem ser tomados de cabeça para baixo, pois eles aparecerão quando resolver voltar! Cada uma dessas operações é complexa, rica em elementos cognitivos, espaciais, afetivos. Em uma simples transferência de sua casa para a loja de frutas a criança pode descobrir pedras de várias cores, folhas secas, pequenos animais, folhas de revistas com fotografias estranhas (às vezes não "adequadas" para ela), pode mudar o caminho tomando cuidado para não se perder, deve então explicar ao verdureiro o que tem a comprar, ele tem que pagar, aceitar ou rejeitar a figueira que lhe dá, ir para casa. Quantas coisas terá para contar à mamãe! Para a criança se deslocar é um percurso, um itinerário feito de muitos pontos intermediários cada um dos quais é mais importante do que o ponto de chegada que representa apenas o fim das descobertas e aventura. Exatamente o oposto do adulto. "Se eu tivesse, disse o pequeno príncipe para si mesmo, 53 minutos para gastar eu iria devagar para uma fonte" (SAINT-EXUPÉRY, 1943).

Essa forma de mover o adulto e a criança é uma bela metáfora para entender duas filosofias diferentes da vida, duas formas de lidar não só com o espaço, mas com o tempo, as relações sociais, o aprendizado e o brincar. Para brincar as crianças devem ter, como nas palavras do pequeno príncipe, 53 minutos para gastar e tempo livre, para usar como quiserem. Tempo em que é possível experimentar a sensação insuportável de tédio, de não saber o que fazer e de ter que fazer algo para sair, com um companheiro, com uma ideia, com um brinquedo, inventando algo. Um tempo em que o adulto não precisa, não quer colocar sua autoridade ou sua competência ou mesmo apenas sua vigilância protetora. Um tempo que a criança pode passar. E então você precisa de uma fonte para ir. Não é importante chegar à fonte, mas fazer 
uma viagem, uma exploração, uma busca. Por isso, o espaço que as crianças precisam para brincar deve ser um espaço não limitado, não fechado, não pobre e não feito especificamente para brincar.

Um bebê de alguns meses não deve ser mantido dentro do berço, é melhor deixá-lo com sua velha coberta. Dentro do berço ele parece feliz, com todos os seus jogos em mãos, mas ele não pode sair, ele não pode arriscar ... Com a coberta pode engatinhar para fora, até que escape do olhar atento da mãe ou da adulta que esteja com ele e surge sua primeira aventura. E então um dia ele será capaz de sair pela porta, encontrar outra criança, brincar com ela na escada, no quintal, na calçada. Depois vá com as outras crianças no jardim perto de casa e depois mais longe, cruze a rua, vá para a praça, explore novos lugares, mais distantes, possa observar os adultos, imitar suas atividades, espionar seus comportamentos muitas vezes estranhos de trabalho, briga, amor. Para brincar, uma criança precisa de uma cidade, porque os ambientes para brincar devem poder crescer com as crianças. (PREZZA ET AL., 2000; CHAWLA, 2001). Com essas possibilidades, vão considerar inadequados e contraproducentes os jardins infantis, todos iguais, todos estritamente nivelados e sempre equipados com móveis estereotipados, como balanços, passeios ou os mais modernos praticáveis de madeira. São lugares que sempre permanecerão os mesmos e onde as crianças sempre terão que ir acompanhadas e supervisionadas por seus pais (ADER, JOUVE, 1991).

O então presidente do Conselho Italiano Romano Prodi disse bem no primeiro Fórum Internacional de Cidades Amigas da Criança em Nápoles, em 1997: "Não é mais suficiente dar às crianças cuidados infantis, devemos devolver-lhes as cidades".

\section{$O$ risco de não encontrar riscos}

Uma diferença importante entre ser criança há 40, 50 anos atrás e atualmente é que os pais não estavam lá. Naqueles períodos as crianças podiam viver suas experiências mais importantes, podiam encontrar as novidades, obstáculos, aventuras, riscos. Naqueles tempos, ou pelo menos, especialmente naqueles períodos as crianças estavam crescendo. Elas experimentaram estratégias de socialização com outras crianças: submissões vergonhosas a serem aceitas pelos adultos, as estranhas atividades necessárias para brincar com as crianças do outro sexo, a força necessária para vencer e a força necessária para perder. Elas experimentaram suas habilidades e as submeteram cada vez a julgamentos mais desafiadores sob o olhar atento dos outros. Elas experimentaram a satisfação do julgamento superado e a frustração do fracasso. 
À noite, cansado, sujo e arranhado, depois das reprovações, havia tantas coisas para contar em casa!

Hoje os adultos estão sempre com elas. Essa é a grande diferença. Se não for um pai, é o professor ou o instrutor ou o catequista ou o operador da biblioteca ou brinquedoteca. Se o adulto está presente a criança não pode correr riscos (o adulto está lá de propósito para que isso não aconteça) e não pode nem explorar, descobrir, surpreender (o adulto está lá de propósito para explicar, antecipar, responder) (BLAKELY, 1994; AMERIO, 1999). Na verdade, as crianças não têm mais nada a dizer por que tudo o que vivem ao longo do dia aconteceu na presença de outras pessoas, de testemunhas, de controladores. A impossibilidade de experienciar obstáculos, provas, quando as crianças os considerarem necessários, leva ao acúmulo de necessidades, um desejo de emoções e risco que tenderão a ser cumpridos quando finalmente a autonomia for alcançada, quando o menino, a menina, terão no bolso as chaves da casa nos bolsos ou numa moto. E pode ser perigoso. Trata-se também de uma possível leitura das dificuldades e dramas da adolescência.

Esse desaparecimento da experiência de risco da vida infantil não está apenas presente no contexto mais óbvio de habilidades físicas e experiências concretas. Também podemos vêlo no desenvolvimento cognitivo, social e emocional, por exemplo.

Se a criança não pode explorar, pesquisar, investigar, dificilmente poderá enfrentar problemas desconhecidos com o desejo de enfrentá-los e resolvê-los sozinho, dificilmente será capaz de experimentar a emoção de encontrar soluções novas, pouco ortodoxas, mas eficazes. Piaget (1945) disse que o conhecimento que não é construído é inútil, mas se o adulto está sempre presente é difícil não pedir sua ajuda e aceitar suas respostas, suas verdades (TONUCCI, 1995). A escola se baseia quase exclusivamente nessa relação entre quem sabe, e por isso ensina e quem não sabe, e por isso deve aprender.

No campo social de uma criança hoje é quase impossível viver o risco e a emoção de encontrar crianças desconhecidas com quem experimentar as delicadas estratégias de aproximação, conhecimento e, por vezes, rejeição. Seus colegas de brincadeiras são quase exclusivamente seus colegas de classe ou os filhos dos amigos de seus pais: amizades controladas e controláveis por adultos. Não será fácil escolher um companheiro para a vida adulta se o menino ou a menina não puderam escolher os companheiros de brincadeira quando crianças.

No campo das emoções, muitas vezes, há uma preocupação por parte dos adultos em ceder e, se possível, antecipar os desejos e demandas das crianças. Assim, falta a relação fundamental entre as muitas coisas e experiências desejadas e sonhadas e as poucas que podem 
ser realizadas com grande felicidade e gratidão. É surpreendente ver as reações desproporcionais de adolescentes que vêm ${ }^{6}$ para machucar ou matar em face da rejeição ou derrota. Fica evidente que a frustração não foi uma experiência esperada e elaborada. Se alguém reconhece que a autonomia é importante para o desenvolvimento de uma criança, para que ela possa brincar e ter as experiências necessárias, os adultos devem dar um passo atrás: por um certo período todos os dias, eles não devem estar com elas.

Conversando com as crianças do Conselho Da Criança em Rosário, Argentina, sobre a necessidade e o direito das crianças de poderem sair de casa sozinhas, uma menina de nove anos disse: "Se eles sempre segurarem minha mão, então um dia terão que me deixar e nesse dia terei medo". E um de seus companheiros propôs: "Os adultos devem nos ajudar, mas de longe."

\section{Vamos recomeçar pelas crianças}

Crianças e adultos fazem da realidade um diagnóstico muito semelhante. Ambos reconhecem que a cidade é perigosa, que os carros são muitos, que não respeitam os pedestres, que as calçadas são sujas, mal conservadas e desordenadas, que as travessias de pedestres não são seguras, que há pessoas más por perto. Mas as consequências para um e para o outro são profundamente diferentes. Os adultos dizem: "Já que estas são as condições da cidade, você fica em casa e se você tiver que sair eu vou acompanhá-lo e esperar por você." As crianças dizem: "Já que estas são as condições da cidade, você tem que mudá-las."

As crianças não são resignadas e não podem aceitar conforto, posse de coisas, em troca de sua liberdade. Por outro lado, as crianças, desde cedo, são capazes de interpretar suas próprias necessidades e contribuir para a mudança de suas cidades (HART, 1997). Por isso, vale a pena dar-lhes a palavra, chamando-as a participar, porque talvez em seu nome e para seu bem-estar é possível pedir aos cidadãos adultos as mudanças que eles dificilmente aceitarão e

\footnotetext{
${ }^{6}$ Curiosamente, a experiência de risco é indicada como um valor positivo no estudo de uma das doenças mais graves da infância, como a leucemia. Greaves, geneticista epidemiologista britânico, que estuda os fatores que promovem a leucemia documentou como ser exposto nos primeiros anos a infecções leva a um desenvolvimento do sistema imunológico capaz, pelo menos em parte, de diminuir o risco de leucemia (Wiemels). Em suma, paradoxalmente, as crianças mais "saudáveis", aquelas que nunca estiveram doentes são as mais fracas e expostas aos maiores perigos. Um estudo mostra que adolescentes que tiveram leucemia quando crianças têm uma autoimagem mais positiva e madura do que seus pares que não passaram por essa experiência: são mais "fortes" e mais generosos (MAGGIOLINI ET AL., 2000). Da mesma forma, as famílias que saem da experiência de uma criança com leucemia, positiva e negativamente, parecem mais fortes, mais abertas e mais generosas que outras. A importância do risco como componente fundamental da experiência lúdica também tem sido estudada em psicologia (BRUNER 1976, SUTTON-SMITH, 1997); em etologia (GRAMPO ET AL., 2001); filosofia (BENCIVENGA, 1988).
} 
promoverão para si mesmos - ao mesmo tempo reconhecendo em teoria sua importância e urgência.

Desde 1991, o projeto internacional "A Cidade das Crianças", promovido pelo Instituto de Ciências e Tecnologias da Cognição (ISTC) da CNR, propõe às Administrações Municipais mudar $^{7}$ o parâmetro exclusivamente do adulto, do sexo masculino, do trabalhador e do motorista para o infantil, para baixar o ponto de vista para a altura da criança de forma a não deixar de ver ninguém. A suposição básica é simples, mas também revolucionária: uma cidade que procura ser adequada para crianças é uma cidade onde todos viverão melhor.

A criança, expressando suas necessidades, representa bem as necessidades de todos os cidadãos, desde os mais fracos, aqueles e aquelas com deficiências, os idosos. Por essa razão, pode se tornar o paradigma para uma nova filosofia de governo da cidade. O projeto, ao qual os prefeitos se juntam, envolve a Administração Municipal em um cruzamento, pois não se trata de criar mais instalações ou serviços para as crianças, mas de realmente mudar a cidade. Hoje, mais de sessenta cidades italianas, algumas cidades espanholas e as maiores cidades argentinas fazem parte de sua rede. Roma aderiu ao projeto em 2001 como uma cidade líder.

O projeto "A Cidade das Crianças" avança em dois eixos principais: autonomia e participação das crianças. A perda da autonomia das crianças foi provavelmente o efeito mais retumbante das transformações das últimas décadas na vida das cidades e essa mudança comprometeu sua capacidade de brincar (HILLMAN, 1993). O retorno da autonomia às crianças pode ser um caminho seguro para a recuperação e sobrevivência das cidades. Se as crianças puderem ir à escola sozinhas, brincar com os amigos nos espaços públicos da cidade. Idosos, deficientes e todos os cidadãos poderão aproveitar essa proposta e se encontrar novamente. Além disso, uma maior autonomia também terá um impacto específico sobre as crianças, através de seus efeitos em suas oportunidades de brincadeira: somente se uma criança puder sair de casa, conhecer outras crianças e conviver com elas, sem controle direto dos adultos, suas brincadeiras terão a grande capacidade de envolver plenamente as demais crianças e levá-las a grandes conquistas. Só nessas condições o jogo se torna o protagonista e o brinquedo apenas uma ferramenta do brincar. Somente nessas condições, diante da falta de ferramentas adequadas, as crianças procedem à construção de seus brinquedos utilizando materiais naturais ou recuperando criativamente os materiais rejeitados ${ }^{8}$. Caixas de embalagem,

\footnotetext{
${ }^{7}$ Para uma melhor compreensão das motivações, propostas e experiências do projeto, você pode consultar os volumes de Tonucci 1996; Tonucci 2002 e o site $\underline{w w w . l a c i t t a d e i b a m b i n i . o r g}$

${ }^{8}$ Sim ver as observações de John Locke, no final do século XVII, sobre se as crianças, tanto quanto possível, devem adquirir seus próprios brinquedos (LOCKE, 1970 p. 141-143, 175-178, 271-275).
} 
garrafas plásticas, pedaços de madeira, terra e areia, sempre permitem jogos diferentes e duradouros. Todas as pesquisas mostraram que o único antídoto real para o uso excessivo e acrítico da televisão é a possibilidade de as crianças saírem de casa e se encontrarem. Pelo contrário, é sempre frustrante para o adulto e para a criança a aplicação rigorosa de horários ou regras para limitar o uso da televisão. Quando as famílias avaliam que a cidade não permite mais que as crianças saiam de suas casas, a grande questão que tem sido levantada é o que fazer para passar o tempo. A resposta "mais apropriada" obtida pelos pais e que advém da produção comercial foi a abertura de lojas dedicadas exclusivamente aos brinquedos (cinquenta anos atrás não existiam) e agora os supermercados reais do brinquedo (BENCIVENGA, 1995; KLINE, 1995; SUTTON-SMITH, 1986). Mas o mercado fez mais, colocou brinquedos, especialmente para crianças mais novas, à venda nas farmácias e, com isso, sugere uma ideia diabólica que aproxima a criança do doente, frágil, dependente de cuidados.

No projeto "A Cidade das Crianças", a participação das crianças deve ser buscada e desejada como cumprimento adequado do artigo 12 da Convenção das Nações Unidas sobre os Direitos das Crianças, que diz que as crianças têm o direito de expressar sua opinião sempre que as decisões forem tomadas em relação a elas, e que sua opinião deve ser levada em conta. Como a Administração de uma cidade toma decisões que sempre afetam as crianças, é necessário encontrar as formas adequadas para obter sua opinião (TONUCCI; RISSOTTO, 2001).

Há uma tradição de 30 anos, originária da França, que, no intuito de fazer as crianças entenderem o funcionamento do Conselho Municipal, propõe às crianças e jovens que repitam sua formação e funcionamento em uma espécie de jogo de role-playing em que as crianças formam partidos, participam das eleições, elegem um prefeito e uma junta operando de acordo com o modelo adulto. Trata-se de uma proposta requintadamente educativa que não interfere em nada nas escolhas e na governança da cidade. A proposta do projeto "A cidade das crianças" é puramente política e evita qualquer hipocrisia de pequenos administradores, pequenos prefeitos. Em vez disso, é um grupo de crianças que dão conselhos ao prefeito. Para entender seu significado

O prefeito de Roma, Walter Veltroni, ${ }^{9}$ disse na abertura do primeiro Conselho infantil da cidade: "Eu queria este Conselho porque preciso do seu conselho, da sua ajuda. Acontece

\footnotetext{
${ }^{9}$ Em Roma, foi criado um Conselho Infantil composto por uma criança e uma menina, uma quarta e uma quinta série (9-10 anos), uma escola para cada uma das 19 Prefeituras. Os conselheiros são nomeados por sorteio e permanecem no cargo por dois anos. O Conselho se reúne uma vez por mês, durante o horário escolar, durante toda a manhã. Duas vezes por ano, o Conselho da Criança se reúne com o prefeito e o Conselho Municipal. Como
} 
que os adultos esquecem de quando eram crianças. Eles não se lembram das coisas importantes e necessárias para viver bem esse tempo da vida. Esquecem dos sonhos, dos desejos e da esperança de quando se é criança e se tem toda a vida pela frente. A partir de hoje começamos a trabalhar juntos porque queremos mudar a cidade." A partir desse momento, as crianças começaram a trabalhar para aconselhar o prefeito, sugerir ideias e protestar pelo que não gostavam. A partir desse dia começaram a participar do governo da cidade. Desde aquele dia, os adultos estão em dificuldade, muitas vezes deixando de dar respostas adequadas às solicitações sempre motivadas e precisas das crianças.

Há também outras propostas para que os cidadãos com menos de 18 anos participem das decisões públicas. Já há algum tempo, por exemplo, fala-se em voto universal, ou seja, a concessão do direito de voto a todos os cidadãos desde o nascimento. O voto dos menores seria, segundo essas propostas, exercido pelos pais, seus responsáveis legais, ou, em algumas propostas, pelas mães, para reequilibrar a participação das mulheres na vida pública (VAN PAREIJS, 1988). Esse debate entre filósofos e estudiosos da ciência política levou, nos últimos anos, a propostas parlamentares concretas, por exemplo, na Alemanha.

Embora ache esta proposta interessante, pois poderia incluir novos elementos no já cansado debate político (TONUCCI, 1996), não creio que possa responder satisfatoriamente ao direito das crianças de participar nos termos do artigo $12^{\circ}$. Ainda seriam os adultos a tomar as decisões, ainda que em nome de seus filhos. O Conselho da Criança, por outro lado, poderia, se devidamente conduzido, realmente reunir as opiniões dos pequenos.

Resta saber se é necessário consultar as crianças se os problemas e erros das cidades são tão claros para todos os especialistas que lidam com elas tanto do ponto de vista psicopedagógico, quanto urbano. Pela experiência desses quase quinze anos, acreditamos que podemos responder afirmativamente por pelo menos três motivos. 1. As crianças são capazes de apontar problemas que os adultos tendem a não ver ou subestimar, como a falta de espaço e tempo para brincar, o absurdo da proteção excessiva, a impossibilidade de mobilidade autônoma, etc. 2. Os administradores podem se tornar fortes diante de seus concidadãos considerando as demandas das crianças para incitar mudanças mais caras. Eles podem dizer "Seus filhos pedem por isso". 3. Para as crianças, a participação real no governo municipal torna-se uma forma forte e direta de educação para a democracia.

esta é a experiência que o ISTC está a acompanhar com mais força, as propostas deste Conselho serão relatadas a seguir. 


\section{Experiências}

Vamos agora tentar refazer o significado da autonomia das crianças e sua necessidade de brincar através do seu ponto de vista e das propostas e demandas que as próprias crianças têm apresentado em algumas experiências de participação infantil no governo das cidades.

"Queremos permissão desta cidade para sair de casa." A pré-condição para que a brincadeira infantil exista é que as crianças saiam de casa sem estarem acompanhadas pelos pais. O Conselho da Criança de Roma dedicou um ano inteiro de trabalho a este problema. Em sua reunião final, em junho de 2002, costumeiramente mantida pelo Conselho da Criança com a Câmara Municipal, com o prefeito e a junta, Federico, um vereador de 11 anos, resumiu o trabalho feito com este pedido: "Queremos permissão desta cidade para sair de casa". Um pedido surpreendente porque uma criança só pode pedir isso a seus pais e só eles podem conceder ou negar. Mas Federico sabia que seus pais o negariam "porque a cidade não permite" e então ele vai até o prefeito e diz a ele "então você me dá permissão para sair de casa". Desde então, o pedido de Federico tornou-se um programa de trabalho para a cidade de Roma que questiona como é possível aumentar a autonomia das crianças em uma cidade tão grande e complexa. O problema é importante porque diz respeito a uma das questões mais sensíveis do debate atual e, provavelmente, do futuro das nossas cidades, o da segurança urbana.

A proposta mais comum para resolver o problema da segurança urbana é o aumento da defesa: aumento das defesas individuais das portas blindadas às armas pessoais, aumento das defesas sociais da polícia para as câmeras nas ruas. Mas essas soluções sempre se mostraram ineficazes e é verdade que os Estados Unidos, que é o país há muito investimento em defesa, continua a ser um país altamente inseguro ${ }^{10}$. Os habitantes de algumas Prefeituras da grande Buenos Aires, o grande cinturão urbano de 8.000.000 habitantes ao redor da cidade de Buenos Aires, estavam cansados da violência contínua e dos assaltos que seus filhos sofriam. Devido a essa insatisfação decidiram não pedir mais presença policial, mas maior participação dos moradores dos bairros para garantir segurança às crianças nos caminhos de casa à escola, de acordo com as indicações do nosso projeto "A Cidade das Crianças"11. Comerciantes e artesãos,

\footnotetext{
${ }^{10}$ Diante das quase 3.000 vítimas do terrível ataque de 11 de setembro no mesmo ano, 30.000 pessoas morreram em acidentes causados pelo uso de armas de fogo (Fonte: MANN, M., O império impotente: Piemme, 2004).

${ }^{11}$ Clarin, o jornal argentino mais popular, dedicou vários artigos a esta iniciativa. Em 16 de julho de 2003, em um artigo intitulado "Pessoas se une para Se cuida um o caras no caminho para Escola" (As pessoas se unem para proteger as crianças que vão à escola) faz referência explícita ao projeto 'Cidade das Crianças' e considera $90 \%$ a redução dos atos criminosos após o bairro, comerciantes e idosos se mobilizarem para garantir a segurança das
} 
idosos e outros cidadãos estavam envolvidos na recriação da vigilância social nos caminhos das crianças e, segundo os promotores, os atos de crime contra crianças despencaram em $90 \%$. A proposta se espalhou por muitas Prefeituras e está ganhando espaço na Capital Federal. Essa iniciativa tomada na Argentina, e a mesma existente em muitas cidades italianas é chamada de "Na escola vamos sozinhos", que propõe que crianças do ensino fundamental, de seis a onze anos, possam ir à escola com seus amigos e sem o acompanhamento de adultos.

Essas experiências escondem a profunda crença de que as crianças na rua tornam o caminho seguro, são as crianças que vão à escola, que brincam com amigos, reconstroem ao seu redor preocupações e solidariedade de vizinhos que, acreditamos, estão desaparecendo das cidades. É claro que, se todos acompanham seus filhos, se os idosos e deficientes permanecem trancados em casa, tudo é reduzido à dimensão privada e ninguém se encarrega dos outros. Mas se as crianças reaparecem, um novo bairro é construído e produz proteção e segurança. As crianças estão seguras e as pessoas estão envolvidas e satisfeitas: "É bom ver as crianças indo para a escola sozinhas", me disseram várias vezes os moradores dos bairros que vivenciaram com sucesso a experiência "Na escola vamos sozinhos" (BARALDI; MAGGIONI, 2000; RISOTTO; TONUCCI, 2002; PREZZA EL AL., 2010; SHAW ET AL., 2013).

Se a segurança e, portanto, a possibilidade de sair é uma pré-condição para brincar, então há duas condições necessárias que falharam e que as crianças exigem claramente: Lazer e Espaço Público.

Tempo livre para brincar. Discutimos com os filhos de Florêncio Varela, na Argentina, se os dois artigos da Convenção dos Direitos da Criança de 1989 , o $28^{\circ}$ e o $31^{\circ}$ que afirmam os direitos à educação e o de brincar tiveram um peso igual em seus cotidianos. É claro que as crianças têm dito que este não é o caso, que o brincar não é considerado importante pelos adultos e que muitas vezes eles não têm tempo para brincar, enquanto isso, as crianças têm sempre que ter tempo para ir à escola ou fazer a lição de casa. Na verdade, em sua opinião, o direito de ir à escola é sentido principalmente como um dever e o direito de jogar como algo que os adultos consideram perder tempo. Imaginamos então que o direito de brincar também deveria ser considerado um dever e definimos quantas horas uma criança teria que brincar todos os dias para cumprir esse dever. Divertia muito as crianças a ideia de que poderiam ir à escola uma hora mais tarde ou não irem, se tivessem que compensar as horas que não puderam brincar no dia anterior porque estavam ocupados fazendo lição de casa ou acompanhando os pais, por exemplo, ao supermercado. Desta forma, o problema realmente parece um paradoxo, mas se as 
considerações iniciais sobre a importância do brincar são verdadeiras, esta proposta deve ser considerada de uma forma muito mais séria. Não como um investimento para o futuro, como se costuma pensar, mas para o presente: as crianças que brincam na cidade produzem mudanças e melhorias a partir de hoje, de imediato.

As crianças do Conselho Infantil de Roma, tendo feito a mesma jornada que os argentinos, envolveram seus colegas de escola em uma investigação sobre os problemas que as crianças encontram em relação ao brincar. $\mathrm{O}$ maior problema foi a falta de tempo e a proposta mais citada para aumentar o tempo de brincadeira era ter menos dever de casa. O Conselho da Criança então escreveu uma carta aberta a todas as escolas primárias de Roma pedindo aos seus professores que não tivessem mais lição de casa nos fins de semana e feriados. As crianças se propõem a estar dispostas a fazer, nesses períodos, algumas atividades, mas apenas aquelas desejadas e sem controles. As crianças não são pedagogas e não se expressam sobre a validade das tarefas. Elas só consideram que a escola não pode tomar todo o seu tempo e exigem que uma parte limitada seja devolvida a eles para que possam brincar. Silvia, no entanto, uma conselheira de 10 anos, faz uma avaliação pessoal: "Com a lição de casa você não desenvolve a imaginação, com a brincadeira sim". É surpreendente que vários resultados científicos confirmem exatamente a tese de Silvia.

A demanda das crianças romanas teve uma grande ressonância na mídia, tanto local quanto nacional, muitos especialistas têm se expressado a seu favor, mas infelizmente os velhos hábitos mudaram em poucas escolas. Para isso a escola deveria estar muito interessada em saber se os alunos podem dedicar suas horas vespertinas, finais de semana e feriados a experiências interessantes de exploração e se podem brincar com seus colegas de classe, pois essas experiências podem ser um alimento fundamental para o trabalho escolar. Na ausência dessa contribuição dos alunos, a escola será forçada a retornar aos seus programas e livros didáticos, voltando a ser uma escola ruim.

Um espaço público para brincar. A segunda condição necessária para poder brincar, uma vez que se possa sair de casa fora de controle e ter tempo livre para fazê-lo, é ter lugares para ir. Já foi dito que os jardins infantis não são lugares adequados para uma atividade tão importante como a brincadeira. Para brincar as crianças precisam de um espaço que cresça com suas habilidades e sua autonomia. Um espaço que possa acompanhar seu desenvolvimento, que saiba oferecer novas experiências, novas descobertas. As crianças precisam brincar na cidade, nem mais nem menos.

A este respeito, as crianças do Conselho da Criança de Roma fizeram uma descoberta perturbadora: no Regulamento da Polícia Urbana o artigo $6^{\circ}$ diz: "É vedada qualquer 
brincadeira sobre solo público". Acreditando que este artigo era contrário ao artigo 31 da Convenção sobre os Direitos das Crianças, que é lei nacional italiana desde 1991, eles escreveram ao prefeito pedindo-lhe para alterar esse artigo.

$\mathrm{O}$ prefeito respondeu às crianças reconhecendo corretamente seu protesto e prometendo mudar o artigo $6^{\circ}$ do Regimento. Após essa vitória, as crianças do Conselho deram mais um passo e escreveram uma carta às assembleias de condomínios em toda a cidade instando os conselhos a rever as regulamentações condominiais que muitas vezes restringem ou proíbem crianças de brincar. O prefeito também apoiou este segundo pedido das crianças e pôde acompanhá-lo com seu próprio convite aos cidadãos romanos. O protesto das crianças romanas poderia, portanto, ter consequências importantes: fazer com que a proibição de placas de jogos desapareça de locais públicos da cidade, abrir um debate por toda a cidade sobre o direito das crianças brincarem nos espaços comuns de suas casas e condomínios e, esperamos, provocar tal fenômeno em outras cidades que quase sempre têm artigos do Regulamento de Polícia Urbana semelhante ao artigo $6^{\circ}$ de Roma.

Mais jogo para todos. Em 1998, o Conselho Da Criança do Distrito Norte da cidade de Rosário, Argentina, durante reunião extraordinária da Câmara Municipal, com a presença de dezenas de crianças que representam as escolas da cidade, convocou a criação do "Dia do Brincar" como um evento anual com as seguintes características: cairá todos os anos na primeira quarta-feira de outubro; as escolas estarão abertas apenas para brincar; os funcionários públicos terão uma hora paga para brincar; algumas ruas da cidade serão fechadas para o trânsito. Vale a pena examinar essas condições que contêm elementos altamente inovadores e que, como muitas vezes é o caso, superam o puro interesse das próprias crianças. 1. O dia solicitado será chamado de "Dia do Brincar" e não "Dia das Crianças". Nas discussões que o Conselho da Criança dedicou a esta importante proposta, a análise das crianças preocupou não apenas sua categoria, mas toda a cidadania. Na sua opinião, os adultos brincam pouco ou não brincam mais e isso cria muitos problemas, tanto para adultos quanto para crianças. "Se os adultos brincassem mais, eles seriam melhores", disseram. A proposta é, portanto, ter um dia por ano em que todos sejam convidados a brincar. 2. O dia terá que ser um trabalho, não para ganhar um dia de férias, mas para quebrar o esquema adulto de trabalho separado do prazer, do brincar, da relação com os outros. Terá que estar funcionando para que as escolas estejam abertas, mas abertas apenas para brincar: professores, pais e filhos terão que preparar esse dia especial. É divertido pensar que uma vez por ano na escola você só vai por prazer e provavelmente essa "gramática" pode fazer muito bem para a própria escola. 3. Os funcionários públicos devem ter uma permissão especial de uma hora para dedicar ao jogo, para brincar em si mesmos e brincar com as crianças. 
Mais uma vez, as repartições públicas e serviços terão que se preparar para este estranho encontro com as crianças, a fim de oferecer-lhes alguma forma de brincadeira, possivelmente relacionada ao seu trabalho, ao seu papel. 4. Algumas ruas serão fechadas para se tornar um lugar de brincadeiras. Essa última condição, agora comum em nossas cidades, é que em um determinado dia (geralmente um domingo) feche todas ou algumas ruas para deixá-las para o jogo das crianças, nessa experiência adquire um valor maior em um dia de trabalho: adultos livres do trabalho poderão fazer nas ruas algumas brincadeiras com as crianças da cidade.

A Câmara Municipal aprovou o pedido por unanimidade.

Há vinte anos, o "Dia do Brincar" é comemorado em Rosário e a participação de adultos vem aumentando a cada ano. A permissão para deixar o emprego, que era originalmente solicitada por crianças para os trabalhadores municipais (porque o município só podia decidir sobre seus funcionários), foi concedida por mais de 300 instituições, incluindo correios, bancos, empresas públicas e privadas. Em cada um desses locais de trabalho, foram preparados jogos envolvendo adultos e crianças. Esses acontecimentos abrem vislumbres e esperanças em uma sociedade como a nossa, aparentemente apenas interessada em lucro, consumo e fechada a qualquer proposta cultural e solidária.

Em 2014, o Conselho da Criança de Buenos Aires propôs que a "Noite das Crianças" fosse celebrada e há cinco anos crianças de muitos bairros da cidade vêm experimentando exploração e brincadeiras a partir das $21 \mathrm{~h}$ e depois das $23 \mathrm{~h}$ todos se reúnem em um estádio, no escuro, cada um com uma pilha na mão, para um encontro festivo, de canções, de danças.

\section{Conclusões}

É como se a cidade tivesse esquecido das crianças. Fez-se muito por carros, muito por adultos e para as crianças várias coisas foram feitas através dos serviços para a infância, creches, jardins, playgrounds, brinquedotecas, contudo, esses espaços parecem projetados mais para pais que não sabem onde deixar seus filhos do que para atender as reais necessidades das crianças. De fato, nesta cidade as crianças não podem realizar sua atividade mais importante, seu trabalho real, a experiência que condicionará seu futuro mais do que qualquer outra: brincar.

Uma cidade não pode negar aos seus cidadãos a oportunidade de usufruir de seus direitos, pelo menos aqueles definidos e consagrados na lei, e o direito de brincar está consagrado no artigo 31 da Convenção Internacional sobre os Direitos das Crianças.

Uma cidade será capaz de permitir que as crianças brinquem se puder devolver sua função original aos seus espaços públicos. As ruas, calçadas, praças e jardins devem voltar a 
ser locais de encontro e troca, de caminhada. E a cidade deverá fazê-lo também restituindo aos cidadãos o uso público dos salões de entrada e pátios dos condomínios. Nesses espaços as crianças poderão voltar a brincar, se encontrando com adultos e principalmente com os idosos, que poderão voltar a sair de casa.

No Vesúvio, o vulcão de Nápoles, fui apresentado a um líquen que consegue cultivar a pedra de lava, a pedra dura que cobre as encostas da montanha após uma erupção. Esta muda consegue penetrar na lava, esmagá-la e transformá-la lentamente em solo fértil, onde podem crescer as videiras que produzem renomados vinhos vesuvianos.

As crianças podem ser os líquens de nossas cidades: com sua presença, com suas brincadeiras, invadindo espaços públicos, elas são capazes de mudar os comportamentos absurdos e irresponsáveis de nós, adultos, nos forçar a ser mais cautelosos com os carros, estar mais atentos ao que está acontecendo ao nosso redor, respeitar mais o ambiente onde vivemos e onde nossos filhos e netos viverão.

\section{REFERÊNCIAS}

ADER, J., JOUVE, H. "Jogo e contexto urbano". Arquitetura e Arquitetura Comportamento 7, 1991, p. 115-119.

AMERIO, Piero. Il senso della sicurezza. Milano: Unicopli, 1999.

BARALDI, C., MAGGIONI, G. (Eds.). Uma cidade com crianças, projetos e experiências do Laboratório FanoRoma: Donzelli Publisher, 2000.

BATESON, G. A mensagem "Isto é jogar", Nova Iorque: Fundação Josiah Macy Jr., 1956.

BAUMAN, Z. A sociedade individualizada. Cambridge: Polity Press, 2001.

BENCIVENGA, E. Jogando duro. Crítica à sociedade do entretenimento. Mondadori, 1995.

BENCIVENGA, E. Três diálogos. Turim: Bollati Boringhieri, 1988.

BLAKELY, K. S. Concepções de 'pais' sobre os perigos sociais para as crianças no ambiente urbano' Ambientes Infantis 11, 1994, p. 16-25.

BOZZO, L. 'O Jogo e a Cidade', Cityscape 2, 1995, p. 30-33.

BRUNER, J. S. 'Natureza e usos da imaturidade'. In: BRUNER, J. S., JOLLY, A., SILVA, K. (eds.). Jogar. Seu papel no desenvolvimento e evolução. Nova Iorque: Livros Básicos, 1976.

CALLARI GALLI, M. Cultura, gioco, giocatolli. Prefazione in B SUTTON-SMITH, Nel Paese dei balocchi. I giocattoli come cultura, Molfeta, La Meridiana, 2002 
CHAWLA, L. Crescendo em um mundo urbanizador, Paris/Londres: Unesco Publicação/Earthscan, 2001.

GARLING T.; VALSINER, J. (eds.). Crianças dentro do ambiente: Para uma psicologia da prevenção de acidentes, Nova Iorque: Plenum Press, 1985.

GARVEY, Catherine. Play. Cambridge, MA: Harvard University Press. 1977

GERMANOS, D. 'A relação da criança com o espaço urbano: perspectivas Educacional 'cultural', Arquitetura - Comportamento 2, 1995, p. 54-63.

GOMBRICH, E. H. Meditações sobre um cavalo de hobby e outros ensaios sobre a teoria da arte. Londres: Phaidon, 1971.

GRAMPO, M.; NEWBERRY, R. C., BEKOFF, M. 'Jogo de mamíferos: Treinamento para o inesperado', Revisão Trimestral da Biologia 76, 2001, p. 141-168.

HART, R. Participação das Crianças: A Teoria e a Prática de Envolver Jovens Cidadãos no Desenvolvimento Comunitário e Cuidados Ambientais, Londres: Earthscan Publicação Limitada, 1997.

HILLMAN, M. (ed.). Crianças, transporte e qualidade de vida, Londres: Instituto de Estudos políticos, 1993.

HOMEM, M. Incoerente Império. Londres: Verso Books. 2003.

HUIZINGA, J. Homo Ludens. Amsterdã: Panteão Editor, 1939.

KLINE, S. 'A promoção e comercialização de brinquedos: Hora de repensar o paradoxo?', In: PELLEGRINI, A. O futuro da teoria do jogo. Albany: State of New York University Press, 1995.

LOCKE, J. Alguns pensamentos relativos à educação, Indianápolis/Cambridge: Hackett Publishing Company (orig. ed. 1693), 1996.

LYNCH, K. "O Mundo Espacial da Criança", In: MICHELSON, W.; LEVINE, S.V., MICHELSON, E. (eds.), A criança na cidade: Hoje e amanhã, Toronto: Universidade de Toronto Press, 1979.

MARILLAUD, J. 'Jogo e Segurança no espaço Público', Arquitetura - Comportamento 7, 1991, p. 137-145.

MUMFORD, L. 'Planejamento para as diferentes fases da vida', Planejamento urbano 1, 7-11. 1945.

PIAGET, J. A formação do símbolo em crianças. Neuchâtel: Delachaux e Niestlé, 1945.

PREZZA, M.; ALPARONE, F.R.; RENZI, D.; PETERBONO, Um. Participação Social e Mobilidade Independente em Crianças: Os Efeitos de Duas Implementações de "Vamos à Escola Sozinhos", Revista de Prevenção \& Intervenção na Comunidade, 2010, 38, p. 8-25. 
PREZZA, M., PILLONI, S., MORABITO C.; SERSANTE C.; ALPARONE, F. R. 'A mobilidade autônoma das crianças no contexto urbano e no pátio, parque e estrada privada como espaços de jogo', Psicologia da saúde 3, 2000, p. 81-97.

RISSOTTO, A., TONUCCI, F. 'Liberdade de Movimento e Conhecimento Ambiental em Crianças do Ensino Fundamental', Revista de Psicologia Ambiental 22, 65-77, p. 2002.

SAINT-EXUPÉRY, A. O Pequeno Príncipe, Paris: Gallimard, 1943.

SHAW, B., WATSON, B. Serviço para mulheres. REDECKER, B.; JONES, A.; HILLMAN, T. M. Mobilidade independente infantil: um estudo comparativo na Inglaterra e Alemanha (1971 - 2010), Londres: Instituto de Estudos políticos, 2013.

SUTTON-SMITH, B. Brinquedos como cultura, Nova Iorque: Gardner Press, 1986.

SUTTON-SMITH, B. A ambiguidade do jogoCambridge: Cambridge University Press, 1997.

TAYLOR, A. F., WILEY, A., KUO, F. E., SULLIVAN, W. C. 'Crescendo na Cidade Interior: Espaços Verdes como Lugares para Crescer' Meio ambiente e Comportamento 30, 1998, p. 327.

TONUCCI, F., RISSOTTO, A. 'Por que precisamos da participação das crianças? A Importância da Participação das Crianças na Mudança da Cidade' Revista de Psicologia Social Comunitária e Aplicada 11, 2001, p. 407-419.

TONUCCI, F. A Cidade das Crianças. Lateza, 1996.

TONUCCI, F. Se as crianças disserem: agora chega! Lateza, 2002.

TONUCCI, F. Si no os haceis como yo. Madrid: PPC, 1995.

VAN PAREIJS, Philippe. The disfranchisement of the elderly, and other attempts to secure intergenerational justice. Philosophy and Public Affairs 27 (4): 1998, p. 292-333.

VYGOTSKY, L.S. "Desempenhar e seu papel no desenvolvimento mental da criança", Psicologia Soviética 12, 1966,

\section{SOBRE O AUTOR:}

\section{Francesco Tonucci (FRATO)}

Instituto de Ciências e Tecnologias da Cognição - ISTC- Conselho Nacional de Pesquisa E-mail: francesco.tonucci@istc.cnr.it

(iD http://orcid.org/0000-0003-1406-7997 